\title{
Plasticity of brittle epoxy resins during debonding failures
}

\author{
RICHARD E. ROBERTSON, MICHEAL G. SPORER \\ Department of Materials Science and Engineering, and Macromolecular Research Center, \\ The University of Michigan, Ann Arbor, Michigan 48109-2136, USA
}

TSUNG-YU PAN, VIORICA E. MINDROIU

Research Department, Ford Motor Company, Dearborn, Michigan 48121-2053, USA

\begin{abstract}
A remarkably high degree of plasticity in brittle epoxies during debonding failures is reported. The plasticity is exhibited by the presence of ridges on the debonded surfaces having a width and height above the general level of these surfaces of the order of $100 \mathrm{~nm}$. The surfaces of the more rigid substrates from which the debonding has occurred, by contrast, are smooth after debonding. The ridges have been found in several forms: in more or less straight rows parallel to the debonding fracture direction; as irregularly-shapes rings or craters, probably formed from secondary crack growth; as paraboloids, which also seem to be related to secondary crack growth; and as serpentine rows more or less perpendicular to the debonding fracture direction. This behaviour has been exhibited by various epoxy formulations. The $100 \mathrm{~nm}$ widths and heights for the ridges suggest that during debonding, plastic deformation has occurred rather uniformly in the epoxy to a depth below the interface of this order. This behaviour is in contrast to the simple notion of brittle fracture, in which atoms or molecules separate across planes in an elastically strained body. It differs also from the bulk fracturing process with these resins, in which a smaller amplitude, more random ridge and groove texture, referred to as the "basic longitudinal" or "fingering" texture, is seen.
\end{abstract}

\section{Introduction}

The modelling of fracture in brittle materials has been guided largely by notions of the fracturing processes based on inferences from gross observations and gross measurements, such as fracture energy. Though not necessarily wrong, such notions are incomplete and do not suggest the subtlety and complexity of behaviour actually occurring. In the present work, we report microscopic observations from the debonding of brittle epoxy resins from harder substrates in which surprisingly large degrees of plastic deformation have occurred. Although some of the instances were perhaps unusual, seeming to depend on the presence of secondary crack nuclei, they still represent a behaviour that is probably common in brittle fracture but is not readily observed. This is a significant, though perhaps local, ductile response during fracture of quite brittle materials.

\section{Experimental details}

\subsection{Materials}

Two brittle epoxy resins were studied. The first was prepared from Dow Chemical Company's D.E.R. 331 diglycidyl ether of bisphenol-A (DGEBA) epoxy resin that was mixed with a stoichiometric 17.2 p.h.r. (parts per one hundred parts resin) of an experimental aliphatic and aromatic amine mixture (XPR-0544010278-48-1, Un 1760) also from Dow Chemical. This curing agent had been recommended as resulting in a relatively fast cure rate with minimal residual stresses.

The second epoxy resin was prepared from Shell Chemical's Epon 828 DGEBA epoxy resin that was cured with the recommended, stoichiometric 20 p.h.r. of Curing Agent $Z$ aromatic amine also from Shell Chemical.

The first system, the glass rod-epoxy (Dow) composite, was used as the matrix resin for an hexagonal array of glass rods. This was done by assembling the rods in an hexagonal pattern in a fixture, with centres of adjacent rods separated by $1.5 \mathrm{~mm}$, and pouring the epoxy mixture around the rods to a depth of about $6 \mathrm{~mm}$. The epoxy was cured at $50^{\circ} \mathrm{C}$ for $40 \mathrm{~min}$ and post-cured at $175^{\circ} \mathrm{C}$ for $2 \mathrm{~h}$ in an air-circulating oven. The specimens were oven-cooled to room temperature after curing. The specimen dimensions were $38 \mathrm{~mm}$ by $16 \mathrm{~mm}$ and $6 \mathrm{~mm}$ thick.

The glass rods used were $1 \mathrm{~mm}$ diameter Corning Pyrex 7740 borosilicate glass. This glass contains about $80 \mathrm{wt} \%$ silica, $13 \mathrm{wt} \% \mathrm{~B}_{2} \mathrm{O}_{3}$, and less than $5 \mathrm{wt} \%$ oxides of sodium and potassium. Before bonding, the glass rods were cleaned by heating in a furnace at $540^{\circ} \mathrm{C}$ for $2 \mathrm{~h}$, refluxed with isopropyl alcohol for $1 \mathrm{~h}$, and finally dried and kept at $150^{\circ} \mathrm{C}$ in a vacuum oven until use. The rods were used without size or coupling agent.

The second epoxy (Shell) system was made into bilayers, with the first layer aged for some time before 
the second layer was joined to it. For the first layer, the epoxy system was poured to a depth of about $9 \mathrm{~mm}$ into a tray approximately $30 \mathrm{~mm}$ by $120 \mathrm{~mm}$ and cured and post-cured. The curing cycle of cure and post-cure was $2 \mathrm{~h}$ at $80^{\circ} \mathrm{C}$ followed by $2 \mathrm{~h}$ at $150^{\circ} \mathrm{C}$. The resulting slab was cut into pieces and thermally aged at $200^{\circ} \mathrm{C}$ for various lengths of time ranging from 2 to $8 \mathrm{~h}$. The aged pieces then were placed in pans with the original air side up, a second layer of the chemicallysame epoxy system was poured on top of these to about the same depth $(9 \mathrm{~mm})$, and the two layers together were subjected to the above curing cycle.

\subsection{Specimen preparation}

For the epoxy-bonded hexagonal array of glass rods, notched specimens were fractured by three-point bending. The notches were made in the specimens in the centre of one of the long edges by cutting with a saw and sharpening with a razor blade. Fracture was induced with an Instron Universal Testing Machine operating at a cross-head speed of $0.051 \mathrm{~mm} \mathrm{~min}^{-1}$ $\left(0.002 \mathrm{in} . \mathrm{min}^{-1}\right)$. The location of the notch and the bending about an axis parallel with the glass rods induced crack propagation into the crowd of glass rods generally parallel with their axes. The crack propagated either around or through the glass rods depending on the surface condition of the glass rods. The debonding of the rods from the matrix resin was the subject of interest for this study.

The bilayer specimens were cut to a size of about $30 \mathrm{~mm}$ by $40 \mathrm{~mm}$, with a thickness of about $18 \mathrm{~mm}$. A slot approximately $1 \mathrm{~mm}$ wide was machined into the ends of these to a depth of about $2 \mathrm{~mm}$. The slot was centred and parallel with the bonding interface. A screwdriver was placed in the slot and twisted, by hand, until fracture initiated and the specimen fell into two pieces. The stresses inducing fracture were essentially those of mode I cleavage. Although the crack was intended to follow along the "weakened" bond plane, it did so only occasionally. Only the failure along the bond plane is described below.

\subsection{Examination procedure}

The fracture surfaces were examined with a scanning electron microscope (SEM). Prior to this, the fracture surfaces were coated with gold/palladium $(\mathrm{Au} / \mathrm{Pd})$. The SEM employed was a Hitachi S-520, operating at an accelerating voltage of $15 \mathrm{kV}$.

The glass transition temperatures $\left(T_{\mathrm{g}}\right)$ of the Shell epoxy systems were determined with a differential scanning calorimeter (DSC). The transition temperatures cited were selected by the software to be at the midpoint of the range of changing heat capacity. The $T_{\mathrm{g}}$ of the unaged epoxy $\left(156^{\circ} \mathrm{C}\right)$ is $1^{\circ} \mathrm{C}$ above that given in the Shell Epon Resin Structural Reference Manual.

\section{Results}

\subsection{Debonding fracture at a glass-epoxy interface}

We begin by reviewing the findings reported earlier [1] from the debonding fracture of an epoxy matrix resin from the surface of glass rods. As is shown in Figs 1

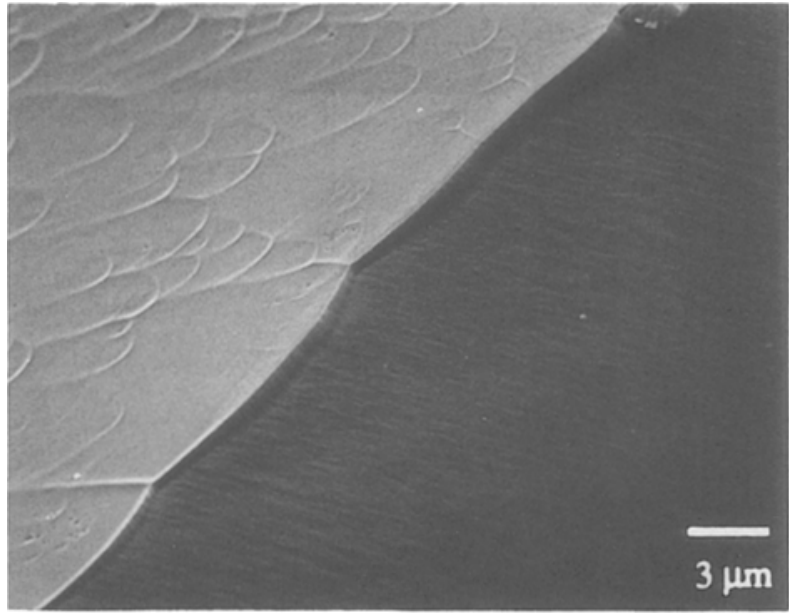

Figure $I$ Epoxy surface after debonding from glass rod. Obtained in the vicinity of where the crack in the epoxy matrix (lower right) first jumped to the rod surface and began debonding the matrix from the glass (upper left) [1].

and 2, such debonding can produce a field of paraboloids on the debonded surface of the epoxy. These paraboloids were produced in the part of the debonding where the angle between the applied tensile stress and the normal to the surface of the rod was generally above $45^{\circ}$. Before the debonding occurred, the crack had been growing in the matrix toward the glass rod, in a direction perpendicular to the rod axis, on a plane normal to the tensile stress. The crack first reached the rod at a point on its surface where the angle between the stress axis and the normal to the rod was roughly $70^{\circ}$ to $80^{\circ}$. The field of paraboloids seen in Figs 1 and 2 was formed from this point and continued around the rod to where the angle between the normal to the surface and the stress axis had decreased to about $40^{\circ}$. The view in Figs 1 and 2 is from near the beginning of the debonding; the texture left by the crack propagating through the matrix is seen in the lower right. As will be mentioned below, the fairly large angle between the surface normal and the stress axis may not have been significant in the formation of the paraboloids.

A stereo pair of micrographs, shown earlier [1]

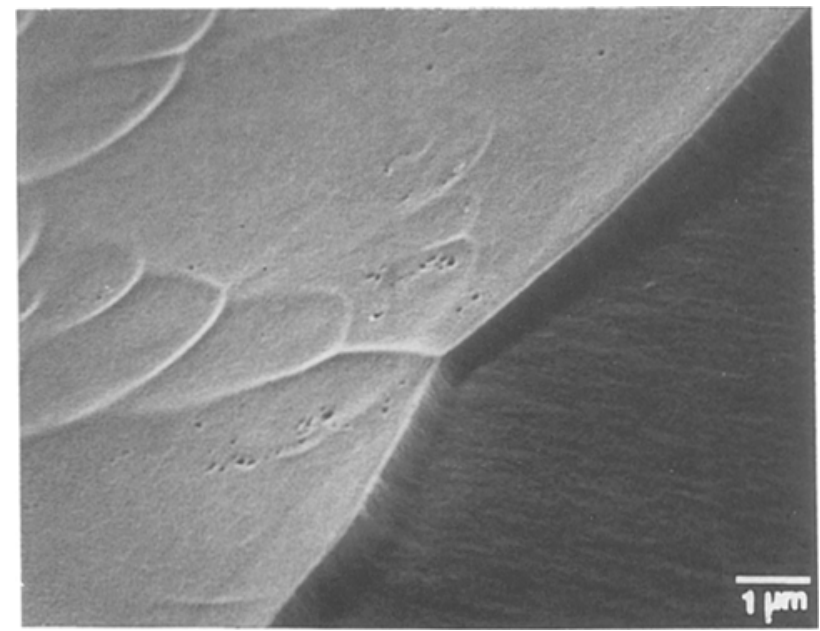

Figure 2 Debonded epoxy surface. Magnified view of that in Fig. 1, showing the white paraboloids on the debonded surface [1] 


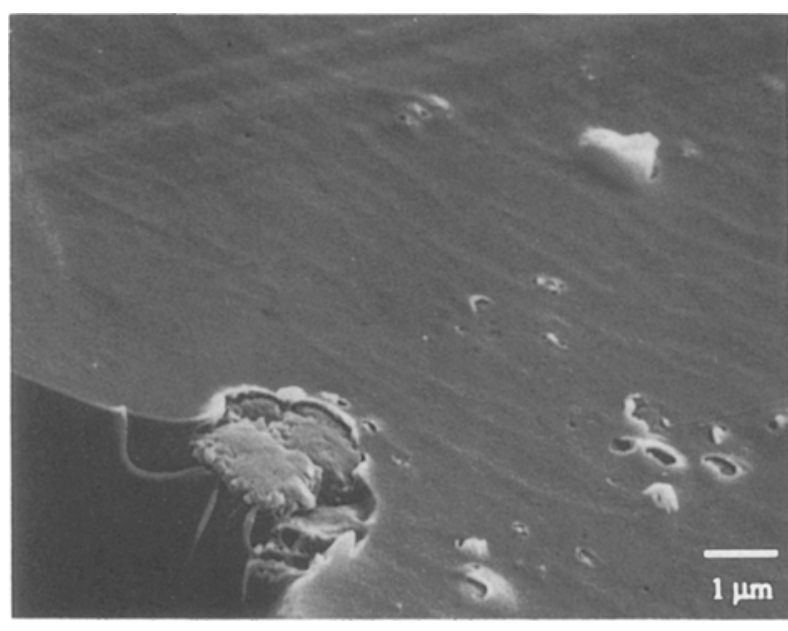

Figure 3 Epxoy surface after debonding from glass rod. Obtained in the vicinity of where the debonding crack jumped from the matrixglass interface into the matrix (lower left). The crack propagated from upper right to lower left. (The jump seems to have initiated at a spot of material that adhered better than average to the glass surface and remained on the glass.) Debonding has resulted in an undulating texture.

demonstrates that the white paraboloids seen in Figs 1 and 2 are ridges. The width or thickness of the ridges is roughly $100 \mathrm{~nm}$, and the ridges are estimated to rise to a height above the surrounding of about the same magnitude. The ridge height is likely to depend on the deformability of the resin, the stress level at the interface, and the general adhesion of the resin to the glass surface. The glass surface exposed by the debonding is everywhere completely smooth.

The field of paraboloids seems to be associated with secondary debonding. Within at least some of the paraboloids, a debonding nucleus was discernable at the focus. Thus, as is thought to occur when parabolas appear on the fracture surfaces of poly(methyl methacrylate) and other materials $[2,3]$, the paraboloids probably result from the intersection of the "primary" debonding with secondary debonding. The fairly uniform size of the parabolas indicates that the fracture process at the interface was sequential and that the secondary crack nuclei were uniformly distributed at the interface and were of approximately equal size intensity or equivalent stress raising intensity.

As the debonding went across the top of the glass rod, more or less perpendicular with the applied tensile stress, no discernible texture was created on the epoxy surface by debonding. But as the angle between the normal to the glass surface and the stress axis increased beyond about $45^{\circ}$, a new texture appeared on the debonded epoxy surface, as can be seen in Fig. 3. Debonding resulted in an undulating texture, with the undulations more or less perpendicular to the direction of debonding. Although not analysed in detail, the undulations are believed also to have resulted from plastic deformation at the epoxy surface. Fig. 3 was obtained in the vicinity of where the debonding crack jumped from the matrix-glass interface into the matrix (lower left). The jump seems to have initiated at a spot of material that adhered better than average to the glass surface and remained on the glass.

\subsection{Debonding fracture at the interface of an epoxy bilayer}

The fracture along the bilayer produced some unusual features, an example of which is shown in Fig. 4.
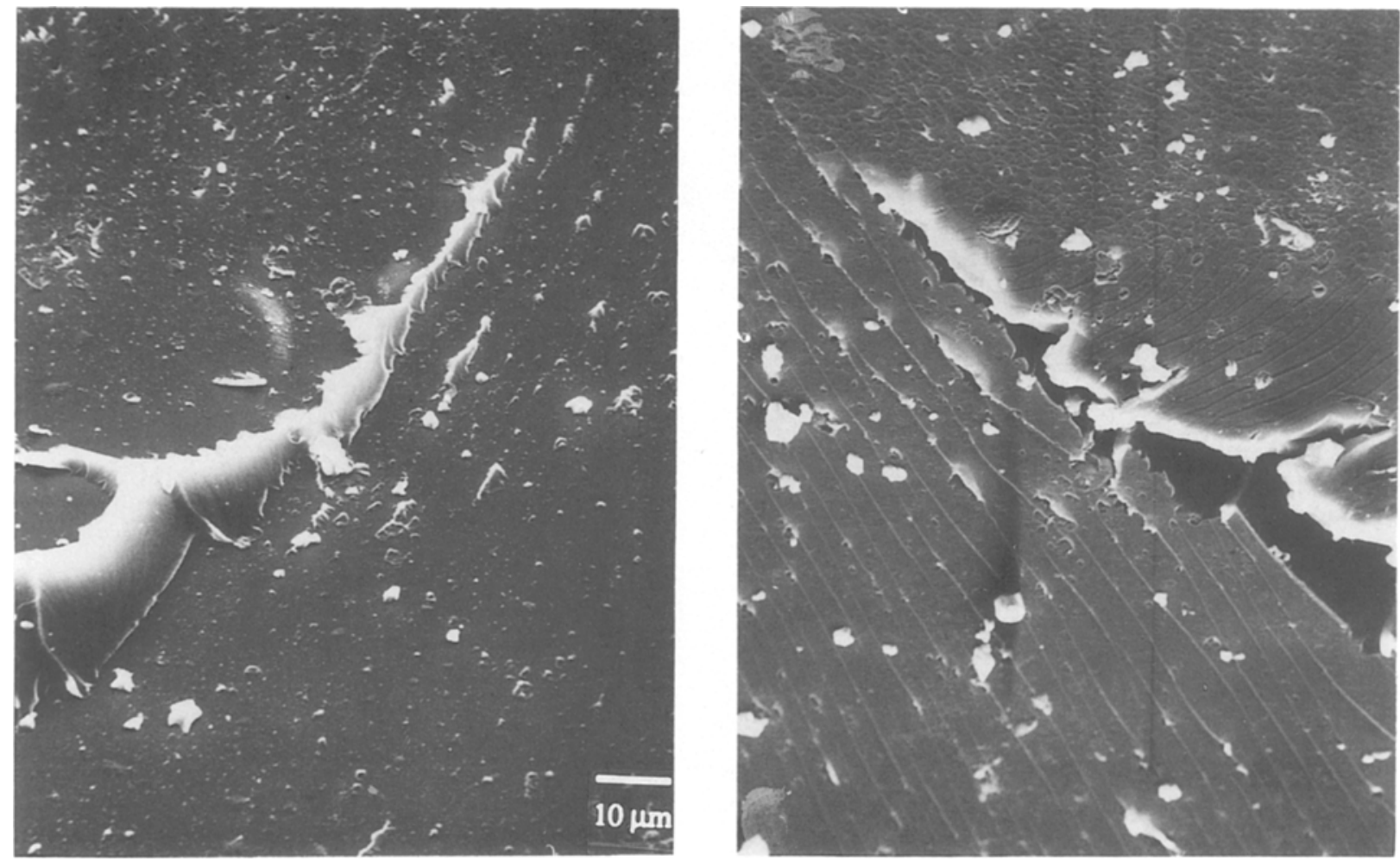

Figure 4 Micrographs of the same region on opposite fracture surfaces after debonding along the interfacial plane of a bilayer specimen. The epoxy on the left had been aged $4.67 \mathrm{~h}$ at $200^{\circ} \mathrm{C}$ before the epoxy on the right had been poured on to this surface and cured. The fracture direction was generally along the axis of the arrow-shaped cut-out. 


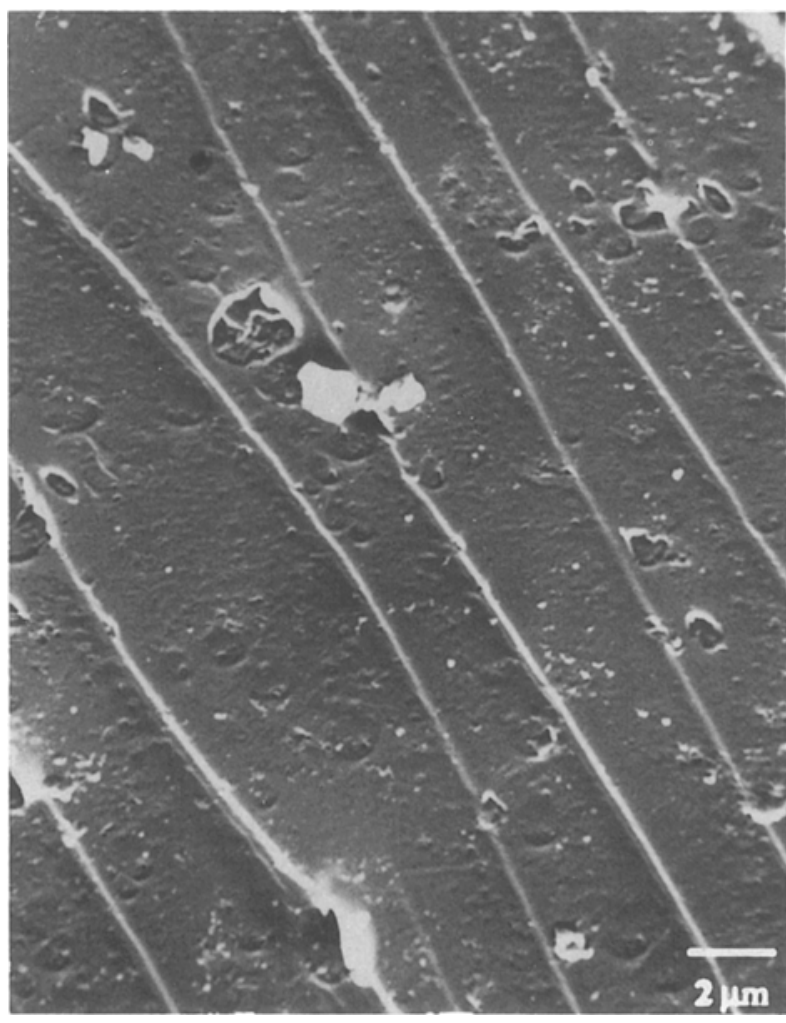

Figure 5 Micrograph at higher magnification of the fracture surface in the right-hand micrograph in Fig. 4, showing a region of the surface below the arrow-shaped depression.

(Other details, particularly those related to the problem of bonding to aged surfaces, are given elsewhere [4].) The two micrographs in Fig. 4 show the same area on the two opposite fracture surfaces. Thus, the arrow-shaped material adhering to the surface on the left is seen to have been taken from the depression in the surface on the right. The surface on the left is that of a slab of epoxy that had been aged for $4.67 \mathrm{~h}$ before the material on the right had been poured on to it and bonded to it. Although there may be some pits on the left micrograph, in the upper left corner where pieces may have been pulled from this slab, there is otherwise no discernible deformation of this piece. (As will be noted below, it is likely that the markings on the left-hand surface in Fig. 4 are due to something that may have been on the surface before this slab had been cured.) In contrast, the surface on the right shows a considerable amount of surface deformation. Below the arrow-shaped depression on this surface, a number of streaks, running diagonally toward the upper left, are visible. Above the arrow-shaped depression are visible a few streaks running the other way, diagonally towards the upper right, and a field of shallow craters.
The streaks below the arrow-shaped depression in the micrograph on the right of Fig. 4 are shown at higher magnification in Fig. 5. This micrograph reveals the streaks to be ridges, roughly $200 \mathrm{~nm}$ in width. Stereo-pair micrographs indicate an elevation that in cross-section may have looked like that in Fig. 6 immediately after separation between the two pieces. As observed in the stereo-pair, however, the ridge heights are not as high as suggested by Figs 5 and 6 nor as peaked as indicated in Fig. 6. Rather, the ridges appear to be relatively low and rounded, but are likely to have become so by retraction after separation. A further indication that the ridges were the last to separate from the opposite surface comes from the remnant debris on this surface (the left-hand micrograph in Fig. 4). Lines of debris just to the right of the tip of the arrow shape in the left-hand micrograph are visible that match the ridges in the right-hand micrograph, and the debris itself matches the notches in the ridges. This is not as noticeable in Fig. 5, which was taken from a region toward the base of the arrow, where relatively little organized debris was left on the surface in the left-hand micrograph.

The texture above the arrow-shaped depression in the right-hand micrograph in Fig. 4 is shown at higher magnification in Fig. 7 and again in Fig. 8. (These two micrographs were taken at slightly different angles with respect to the surface normal, and this has changed the shading enough for what looks like a depression in one to look like an elevation in the other, and vice versa. Irrespective of their appearance, one should remember that the streaks are elevations.) The field of shallow craters in the upper parts of Fig. 7 and 8 and of the right-hand micrograph in Fig. 4 are associated with the surface roughness above the arrow shape on the surface in the left-hand micrograph of Fig. 4 . The roughness suggests a fine particulate dust that may have been on this surface as it was being cured. This could have initiated the multiplicity of secondary debonding that seems to be represented by the field of craters. The density of craters may have had a strong influence on the separation between the ridges. One might note in Fig. 8 that the craters at the edge of this field of craters seem to feed as semicircles into the space between the ridges.

\section{Discussion}

The general and surprising aspect of the above findings is the very large degree of plastic deformation that has occurred during the debonding of these nominally very brittle epoxy resins. The plastic deformation has resulted in ridges being formed, from material having been pulled up from the surface by a seemingly

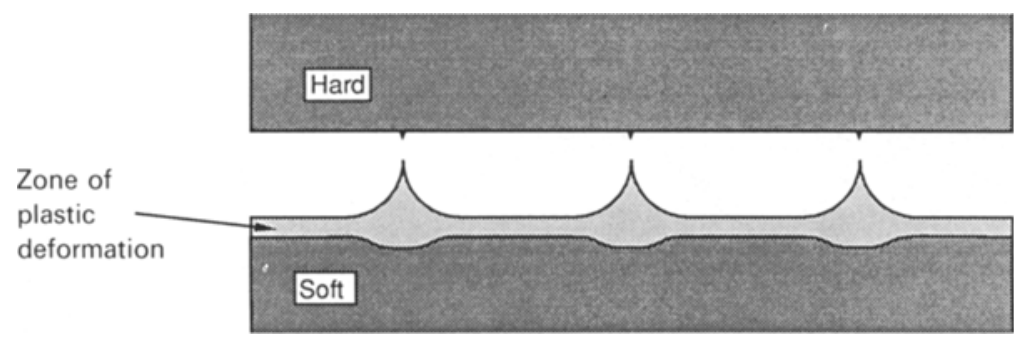

Figure 6 Cross-section through the two fracture surfaces in Fig. 4 immediately after separation, inferred from stereo-pair micrographs of images like that in Fig. 5. 


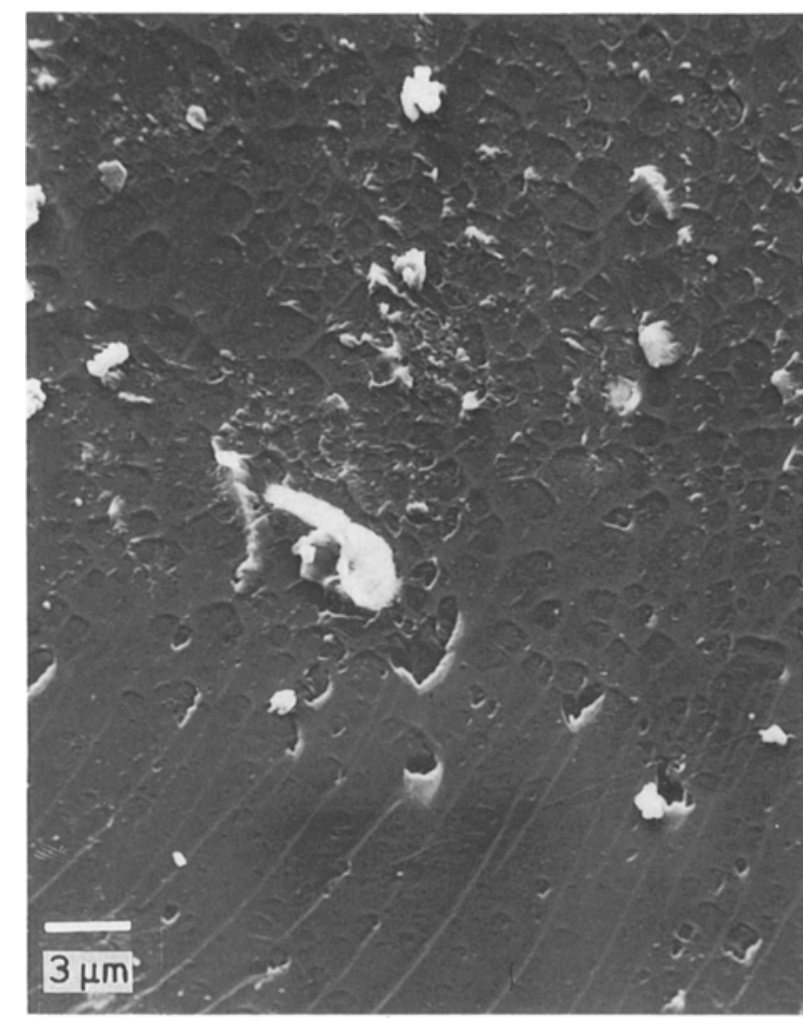

Figure 7 Micrograph at higher magnification of the fracture surface in the right-hand micrograph in Fig. 4, showing a region of the surface above the arrow-shaped depression.

extraordinary amount. Furthermore, the ridges are arranged in various shapes: irregularly shaped circles or craters, parallel ridges oriented with the direction of crack growth, parallel ridges like corrugations oriented perpendicular to the direction of crack growth, and as paraboloids.

The occurrence of the plastic deformation suggests the presence of the following three conditions: significant adhesion, the conversion of mechanical work to heat, and shear softening. Because the ridges were pulled out during the separation of the surfaces, it seems most natural that it could only have happened if there had been adequate adhesion. Indeed, as is described more fully elsewhere [4], the fracture energy for crack growth along the bonding interface to the aged surface, for example, is still about one-half or more of that for crack growth through the bulk epoxy.

\subsection{Thermal effects}

The role of thermal softening, from the conversion of mechanical work through plastic deformation to heat, is the least established of the conditions. It is more

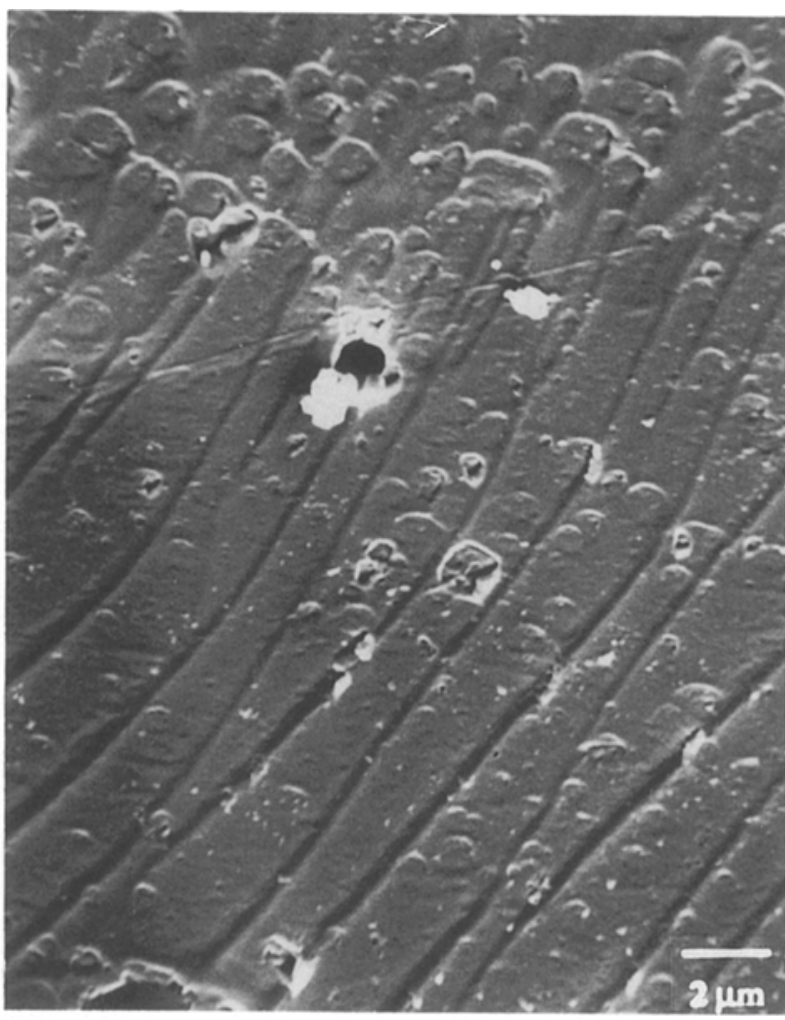

Figure 8 Micrograph at slightly higher magnification and centred slightly below that in Fig. 7 .

likely to be of secondary rather than of primary importance, but its influence probably should not be dismissed. Swallowe et al, reported recently [5] that for thermoplastics like polystyrene, poly(methyl methacrylate), and polycarbonate, which are not expected to behave significantly differently from the thermoset epoxies studied in this work, the temperature of the material immediately adjacent to the crack surfaces can approach $200^{\circ} \mathrm{C}$ above ambient. A diagram indicating a possible geometry for debonding and the region of maximum shear strain accompanying the debonding is given in Fig. 9. (This diagram is suggested by the in situ SEM studies of Gilbert and co-workers $[6,7]$.)

The outline of the region of maximum shear strain in Fig. 9, though not well-established, is useful for indicating how heating from the conversion of mechanical work can assist further plastic deformation. The heating would begin at the right-hand edge of the shearing zone and continue to the left-hand edge of this zone. Thus, a temperature increase approaching $200^{\circ} \mathrm{C}$ would be reached only towards the left, away from the crack tip. (The gross conversion of work to

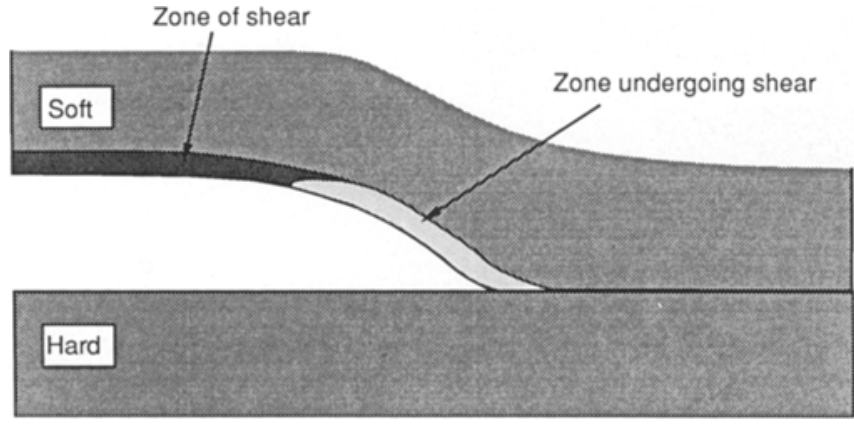

Figure 9 Diagram of a possible debonding geometry and region of maximum shear strain accompanying the debonding. 
heat would predict a temperature greater than $200^{\circ} \mathrm{C}$, but the $200^{\circ} \mathrm{C}$ estimate, being experimental, reflects the loss of heat from the shear zone by conduction [5].) Also, the rate of heat generation will tend to be concentrated towards the left, where the effect of thermal softening is greater. In terms of the applied shear stress and resulting shear rate, the rate of heat generation per unit volume is given by

$$
\begin{aligned}
d H / \mathrm{d} t & =\tau \dot{\gamma} \\
& =\tau^{2} / \eta
\end{aligned}
$$

where $\eta$ is the local effective viscosity. Under some circumstances, thermal softening can decrease the effective viscosity very efficiently. For example, in the vicinity of the glass transition, where thermal softening is most effective, a linear increase in temperature will result in a faster than exponential decrease in viscosity. According to the above equation, then, in regions where the shear stress is not a strong function of position, the decreasing viscosity increases the rate of heat generation towards the left in the diagram. As a result, towards the right-hand edge of the maximum shear region, the temperature rise itself is not likely to be high enough to bring the material into the temperature region of the glass transition. Thus, heating alone is not expected to cause the plasticity. Rather, the heating is expected only to influence the plasticity and to be a result of it.

\subsection{Shear softening effects}

The primary cause of the plasticity seems to be the presence of strong shear stress fields. The normal triaxial stress ahead of the crack front can transform to a shear stress field as pairs of cracks approach each other. Figs 10 and 11 indicate likely mechanisms for the formation of two of the four manifestations of debonding plasticity described above. These are the more or less parallel ridges oriented in the direction of crack growth (Fig. 5) and the field of paraboloids (Fig. 1), respectively. In each, the ridges form just as the cracks on opposite sides of the ridges approach one another. Elsewhere in these specimens, the plasticity is relatively modest. The irregularly-shaped circles or craters in Figs 7 and 8 probably formed in a way similar to that of the field of paraboloids, except that at the moment they formed, they were not in the presence of a propagating primary crack. They seemed to have developed ahead of general fracture, probably from foreign particles at the interface. The orientation of the parallel ridges below the craters in Figs 7 and 8 ,

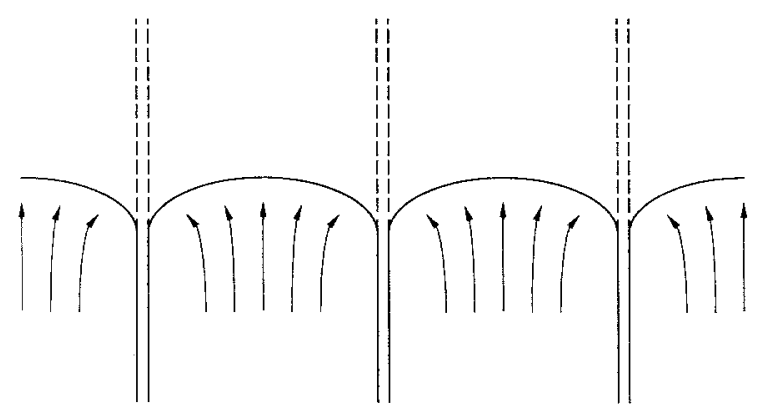

Figure 10 Likely mechanism for the tormation of the more or less parallel ridges oriented in the direction of crack growth.

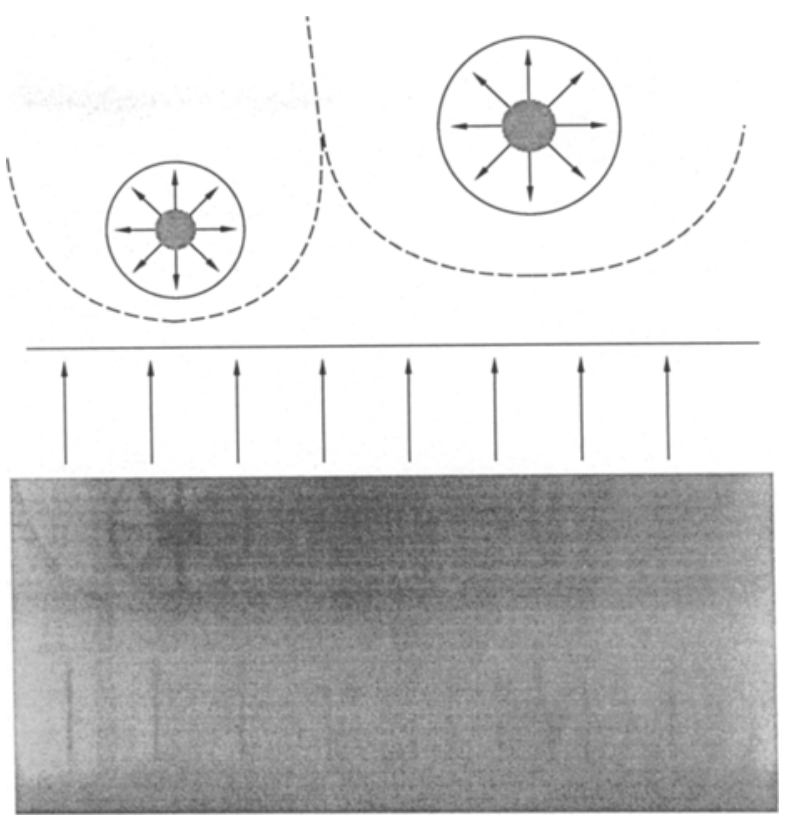

Figure 11 Likely mechanism for the formation of the paraboloid field.

which seemed to have formed subsequently to the formation of the craters, suggest that they were created in a direction running back towards the location of general fracture rather as a spur of the general fracture.

The shear stress field under which the fourth manifestation of plasticity occurred, the corrugations in Fig. 3, probably resulted directly from their orientation. As mentioned above, this texture occurred where the normal to the surface of the glass rod at this location was at a relatively high angle with respect to the applied tensile stress. Thus, the stress experienced at the interface during debonding was largely shear. Rather than being a result of the confluence of opposed cracks, the ridges in the corrugation seem more likely to have resulted from a pulsation in crack propagation, analogous to a stick-slip phenomenon. As softening progresses along the interface, a region of material becomes soft enough that it allows the crack to open wide with the concomitant stretching of this material into a ridge. Following this, the crack seems to spurt ahead with little or no stretching of the material, which is followed by a progressive softening that results in another ridge downstream.

Mechanisms by which a shear stress field can induce softening in a brittle glassy polymer have been discussed elsewhere $[8,9]$. Softening during fracture is expected to be the same as the phenomenon occurring in glassy polymers including thermosets during yielding, as induced by uniaxial tension and uniaxial compression, as well as shear.

A question of interest is whether the parallel ridges oriented with crack growth in Figs 5 and 8 have emerged from "fingering". Fingering processes in fluidized systems have been much studied recently [10-17]. A parameter that can be examined is the separation between the ridges. If the more or less flat space between each pair of ridges represents a growing finger, then the ridge separation should be related to the disturbance propagating through the material 


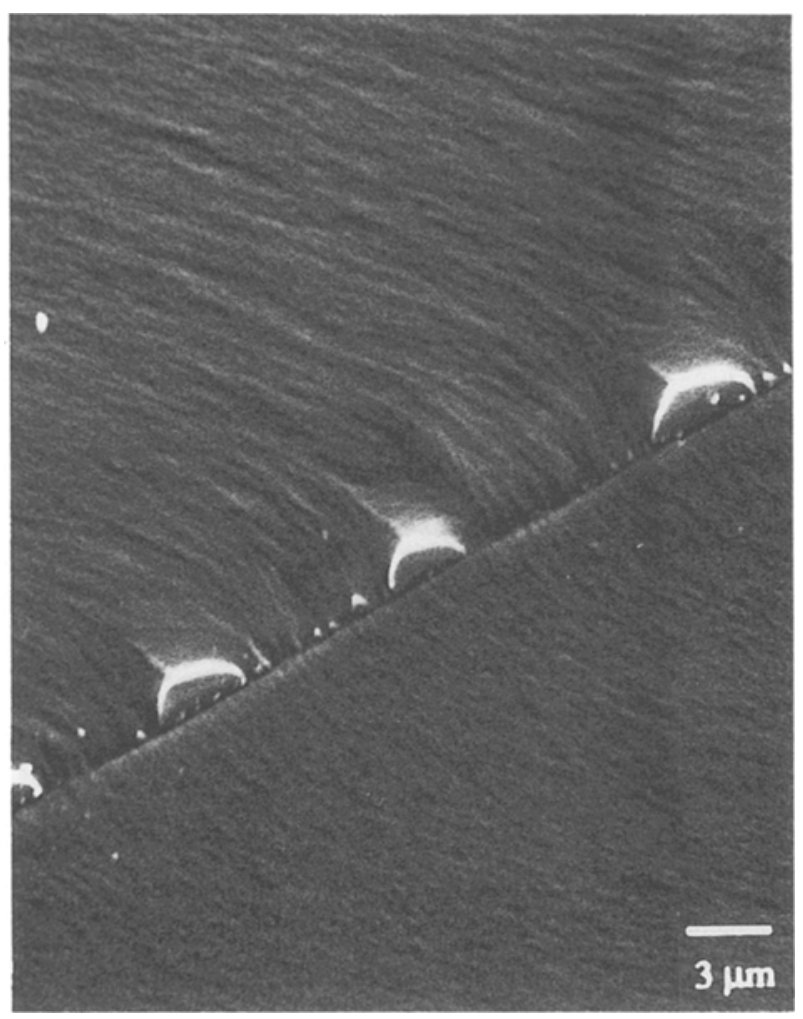

Figure 12 The "basic longitudinal texture" for fracture through the epoxy substrates and across the bond for the epoxy bonded to a thermally aged slab. The aged epoxy is below. The direction of fracture was from lower right to upper left.

most rapidly. Being an instability in the meniscus at the fluidized material-air interface at the crack tip, the finger width that dominates is that which propagates the fastest.

According the Kinloch et al. $[16,17]$ and based on earlier work of Fields and Ashby [10] and Argon and Salama [11], the wavelength of the meniscus instability is given by

$$
\lambda_{\mathrm{c}}=3^{1 / 2} 2 \pi\left(\frac{3^{1 / 2} h G_{0}}{2 \sigma_{\mathrm{y} 0}}\right)^{1 / 2}\left[\frac{3^{1 / 2} \dot{\varepsilon}_{0} h}{2(n+2) \dot{a}_{0}}\right]^{1 / 2 n}
$$

where $\lambda_{\mathrm{c}}$ is the wavelength of the most rapidly growing perturbation, $h$ is the plastic zone thickness, $G_{0}$ is the conserved part of the fracture energy, the part needed to separate atoms linked by primary and secondary bonding, $\dot{\varepsilon}_{0}, \sigma_{\mathrm{y} 0}$, and $n$ are constants in the power-law equation describing the strain rate against yield stress behaviour of the material, and $\dot{a}_{0}$ is the crack velocity.

For a rubber-modified epoxy and a crack speed of $4.2 \mu \mathrm{m} \mathrm{sec}^{-1}$, Kinloch et al. $[16,17]$ estimate a plastic zone thickness of $3.4 \mathrm{~mm}$ or $3400 \mu \mathrm{m}$ and a critical wavelength of $60 \mu \mathrm{m}$. In the present work, where the epoxy contained no rubber inclusions, these dimensions are much reduced. Moreover, the topographic features visible in micrographs such as Figs 5 and 8 suggest that the relationship between the plastic zone thickness and wavelength is just opposite to that found by Kinloch et al. The plastic zone thickness is estimated to be of the order of $1 \mu \mathrm{m}$, but the wavelength measured from Fig. 5 is about $4 \mu \mathrm{m}$. The relative dimensions of plastic zone thickness and wavelength are indicated in Fig. 6. Another texture that we believe is due to fingering is the "basic longitudinal texture". This is shown in Fig. 12 for fracture through the epoxy bilayer, from unaged, across the bond to the thermally aged epoxy. This texture is very different from the widely separated ridges from the surface debonding. The periodicity for the aged epoxy (below the diagonal line separating the two) is about $300 \mathrm{~nm}$; that for the unaged epoxy bonded is about $500 \mathrm{~nm}$. Thus, fingering seems not to have been important in producing the parallel ridges oriented with crack growth. Because, as seen in Fig. 8, the parallel ridges appear to flow out of craters, a more important determinant of the wavelength seems to have been the density of the crack nuclei (dirt) at the interface.

\subsection{Fracture surface asymmetry}

Finally, we should comment on the complete lack, or at least negligible deformation of the material on the opposite surface. In the case of the epoxy bonded to the glass rod, the lack of deformation is not surprising. The elastic modulus of the glass is of the order of 20 times greater than that of the epoxy. Its yield strength is probably higher by an even greater factor. (Though not measurable in uniaxial compression, as is that for the epoxy, one may infer typical behaviour for the glass from that of glass fibres. With pristine E-glass fibres in tension, for example, strains of the order of $4.5 \%$ can be reached without significant inelastic strain; i.e. the yield stress is nowhere in sight even at $4.5 \%$.) The lack of plastic deformation in the aged epoxy layer, in contrast to the unaged epoxy, is more surprising. This is especially so considering that the final glass transition temperatures for the two materials differ by a small amount: $163^{\circ} \mathrm{C}$ for the aged epoxy compared to $156^{\circ} \mathrm{C}$ for the unaged. The contrast simply emphasizes that the behaviour involved is very nonlinear and slightly different responses of the material to the same stress can result in vastly shortened relaxation times that are still decades apart.

\section{Conclusion}

In addition to their significance for adhesive bonding, the above results are indicative of material processes occurring in brittle epoxy fractures, and probably in the brittle fractures of many other materials as well, and suggest a useful technique for observing the presence of these processes. The $100 \mathrm{~nm}$ widths and heights for the ridges suggest that during debonding, plastic deformation has occurred rather uniformly in the epoxy to a depth below the interface of this order. One usually is unable to become aware of such plastic processes in ordinary fracture. The minuteness of fracture surface features make it impossible, in many instances, to examine points on the two opposite surfaces that had been together before fracture. One does not know, for example, whether the grooves of the basic longitudinal texture on one fracture surface correspond to the ridges or to the grooves on the other. Debonding from a planar or slightly curved interface where the materials are of unequal hardness, on the other hand, projects all of the deformation on to a single fracture surface, making its study much simpler. 


\section{References}

1. T.Y. PAN, R. E. ROBERTSON and F. E. FILISKO, J. Mater. Sci. 23 (1988) 2553.

2. J. P. BERRY, J. Appl. Phys. 33 (1962) 1741.

3. Idem, in "Fracture Processes in Polymeric Solids", edited by B. Rosen (Interscience, New York, 1964) p. 195.

4. M. G. SPORER and R. E. ROBERTSON, to be published.

5. G. M. SWALlOWE, J. E. FIELD and L. A. HORN, $J$. Mater. Sci. 21 (1986) 4089.

6. D, J. BROWN, A. H. WINDLE, D. G. GILBERT and P. W. M. BEAUMONT, ibid. 21 (1986) 314.

7. D. G. GILBERT and A. M. DONALD, ibid. 21 (1986) 1819.

8. R. E. ROBERTSON, J. Chem. Phys. 44 (1966) 3950

9. A. S. ARGON and M. I. BESSONOV, Polym. Engng Sci. 17 (1977) 174

10. R. J. FIELDS and M. F. ASHBY, Philos. Mag. 33 (1976) 33.
11. A. S. ARGON and M. SALAMA, Mater. Sci. Engng 23 (1976) 219.

12. A. M. DONALD and E. J. KRAMER, Philos. Mag. Ser. A 43 (1981) 857.

13. R. E. ROBERTSON, V. E. MINDROIU and M. F. CHEUNG, Compos. Sci. Technol. 22 (1985) 197.

14. R. E. ROBERTSON and V. E. MINDROIU, J. Mater. Sci. 20 (1985) 2801.

15. R. E. ROBERTSON and V. E. MINDROIU, Polym. Engng Sci. 27 (1987) 55.

16. A. J. KINLOCH, D. G. GILBERT and S. J. SHAW, Polym. Commum. 26 (1985) 290.

17. Idem, J. Mater. Sci. 21 (1986) 1051.

Received 2 August 1988

and accepted 10 January 1989 